\title{
PENGARUH ACCELERATED LEARNING BERBASIS MUSIK BAROK TERHADAP KEMAMPUAN MEMBACA PEMAHAMAN
}

\author{
Hariyatunnisa Ahmad ${ }^{1}$, Rukayah, Triyanto \\ Universitas Sebelas Maret
}

\begin{abstract}
Reading comprehension is flexible and sustainable cognitive and constructive process. Students 'understanding of reading content is still low, therefore there is need strategies to improve students' reading comprehension ability. One of strategy that can be used in reading comprehension learning is Accelerated Learning based on baroque music. Baroque music has no lyrics and neutral, besides that the baroque music have a strong influence on the ability to absorb information and memorize it. The purpose of this study was to determine differences in scores on the read comprehension ability of fifth grade students of elementary school before and after learning using Accelerated Learning based on baroque music. The design of this study uses nonequivalent control group with data collection techniques using test. The collected data were tested using Independent Sample t-test with a significance level of 5\%. The results showed that there was a significant difference between the score of reading comprehension ability of fifth grade students of elementary school before and after learning using Accelerated Learning based on baroque music.
\end{abstract}

Keywords: reading comprehension, learning strategy, Accelerated Learning, baroque music

\begin{abstract}
Abstrak: Membaca pemahaman adalah proses kognitif dan konstruktif yang fleksibel dan berkelanjutan. Pemahaman siswa mengenai isi bacaan masih belum optimal, oleh karena itu perlu adanya strategi untuk meningkatkan kemampuan membaca pemahaman siswa. Salah satu strategi yang dapat digunakan dalam pembelajaran membaca pemahaman adalah Accelerated Learning berbasis musik barok. Musik barok tidak memiliki lirik dan netral, selain itu musik barok memiliki pengaruh yang kuat pada kemampuan untuk menyerap informasi dan menghafalnya. Tujuan penelitian ini adalah untuk mengetahui perbedaan skor pada kemampuan membaca pemahaman siswa kelas 5 sekolah dasar sebelum dan sesudah belajar menggunakan Accelerated Learning berbasis musik barok. Desain penelitian ini menggunakan nonequivalent control group dengan teknik pengumpulan data menggunakan tes. Data yang terkumpul diuji menggunakan Independent Sample t-test dengan tingkat signifikansi 5\%. Hasil penelitian menunjukkan bahwa ada perbedaan yang signifikan antara skor kemampuan membaca pemahaman siswa kelas 5 sekolah dasar sebelum dan sesudah pembelajaran yang menerapkan Accelerated Learning berbasis musik barok.
\end{abstract}

Kata kunci: membaca pemahaman, strategi pembelajaran, Accelerated Learning, musik barok

\section{PENDAHULUAN}

Membaca merupakan salah satu keterampilan yang penting untuk dikuasai siswa. Alvermann \& Earle (2003); dan Mason (2004) menegaskan bahwa membaca dianggap sebagai kemampuan yang sangat penting untuk dipelajari siswa untuk menunjang kehidupannya di masa yang akan datang. Salah satu kemampuan membaca yang perlu untuk ditingkatkan, yaitu kemampuan membaca pemahaman.

Memahami bacaan merupakan kemampuan yang kompleks yang membutuhkan banyak kemampuan kognitif yang berbeda, karena membaca pemahaman merupakan proses kognitif yang berkelanjutan (Woolley, 2011: 15). Oakhil, Kain, \& Elbro, 2015: 1) menunjukkan bahwa pemahaman adalah hal yang penting, bukan sekadar untuk memahami teks. Membaca pemahaman penting bagi kehidupan sosial saat ini untuk membaca email, teks bacaan, ataupun jejaring sosial.

Berkaitan dengan membaca pemahaman, peneliti mengamati bahwa kemampuan membaca pemahaman bahasa Indonesia siswa masih belum optimal. Hal

\footnotetext{
${ }^{1}$ Universitas Sebelas Maret Surakarta, Email: hariyatunnisahmad国gmail.com
} 
tersebut dikarenakan cara mengajar guru yang masih dominan dengan ceramah, sehingga siswa sangat jarang ikut berpartisipasi dalam pembelajaran dan kurangnya ketertarikan siswa terhadap kegiatan membaca. Siswa juga mudah merasa bosan selama pembelajaran, terlihat dari sikap mereka mengikuti pembelajaran. Siswa juga belum bisa membuat pertanyaan ataupun menjawab pertanyaan dengan tepat berdasarkan isi bacaan, kesulitan menemukan ide-ide pokok bacaan, kesulitan meringkas dan menanggapi bacaan. Sebagaimana yang diungkapkan oleh Gooden, Carreker, Thornhill, \& Joshi (2007), kemampuan membaca pemahaman mencakup menjawab pertanyaan mengenai informasi, menganalisis makna bacaan, menemukan gagasan utama, membuat kesimpulan, penalaran, mensintesis, menetapkan sebab akibat, menentukan hubungan, dan menemukan persamaan.

Melalui wawancara antara peneliti dengan guru, guru mengakui bahwa belum menerapkan metode mengajar yang inovatif maupun yang mampu merangsang minat belajar siswa di kelas. Guru masih menggunakan metode ceramah selama pembelajaran, siswa hanya diminta untuk mendengarkan penjelasan dan mengerjakan tugas sesuai dengan yang ditugaskan oleh guru. Tidak jauh berbeda saat peneliti mewawancarai siswa, siswa mengatakan bahwa mereka merasa bosan selama pembelajaran di kelas, mereka juga tidak bisa menjawab pertanyaan yang diajukan oleh guru. Hasil dokumentasi yang berupa catatan nilai harian maupun nilai ulangan harian maupun ulangan semester siswa menunjukkan hasil yang kurang memuaskan, masih di bawah rata-rata.

Kemampuan membaca pemahaman yang belum optimal diperkuat dengan data skor membaca PISA (Programme for International Student Assessment). Rata-rata skor membaca PISA yaitu 493, namun Indonesia belum mencapai skor rata-rata tersebut. Skor membaca Indonesia berdasarkan data PISA 2015 sebesar 397 (OECD, 2018). Selain itu,
The National Assessment of Educational Progress (NAEP) tahun 2013 dari 51 negara kemampuan membaca siswa sekolah dasar Indonesia berada di posisi ketiga dari bawah (NCES, 2015).

Dari beberapa temuan tersebut, perlu adanya perbaikan untuk meningkatkan kemampuan membaca pemahaman. Perlu adanya perbaikan dalam strategi pembelajaran membaca. Strategi pembelajaran merupakan salah satu faktor untuk meningkatkan kemampuan membaca pemahaman siswa. Seperti yang ditemukan dalam penelitian Sari (2015) bahwa hal yang paling penting untuk meningkatkan skor pemahaman bacaan siswa adalah dengan strategi yang digunakan guru. Salah satu strategi yang bisa digunakan dalam pembelajaran membaca pemahaman, yaitu Accelerated Learning berbasis musik barok.

Accelerated Learning menurut Rose \& Nicholl (1997) tidak hanya menyajikan materi dalam bentuk audio visual untuk diingat siswa, melainkan pembelajaran yang melibatkan aktivitas otak kiri dan otak kanan, agar fakta-fakta yang didapatkan siswa dapat dengan mudah diingat. Accelerated Learning bukan mengajarkan siswa untuk "what we learn?" yaitu hanya mengetahui apa yang sedang dipelajari, tapi "how we learn?" yaitu belajar bukan hanya mengetahui jawabanjawaban, tetapi belajar merupakan suatu proses eksplorasi yang artinya dalam proses pembelajaran siswa terlibat aktif menggunakan seluruh kemampuan yang dimilikinya untuk menemukan konsepkonsep yang melandasi jawaban tersebut sehingga keterampilan siswa akan berkembang. Accelerated Learning merupakan percepatan dan peningkatan belajar yang telah terbukti efektif dapat mempercepat pemahaman dari berbagai materi pembelajaran (Meier, 2000).

Penerapan Accelerated Learning didasarkan pada pembelajaran yang menggunakan musik pengiring selama pembelajaran. Fungsi musik selama pembelajaran untuk menstimulasi otak 
dalam keadaan alpha dan beta. Gelombang alpha terjadi pada saat seseorang mengalami relaksasi atau mulai istirahat, gelombang beta diperlukan ketika otak berpikir rasional dan memecahkan suatu masalah (Rose \& Nicholl, 1997).

Beethoven menyatakan bahwa musik adalah penyeimbang antara fisik dan spiritual (Rose \& Nicholl, 1997). Persyaratan musik yang digunakan dalam pembelajaran adalah musik yang tidak mengandung lirik atau kata-kata, karena hal tersebut dapat mengganggu proses penyimpanan informasi dalam memori siswa, penggunaan musik instrumen dari musik yang memiliki lirik juga tidak diperbolehkan karena dapat membuat siswa menyanyikan lirik lagu dari instrumen yang didengarnya (Gunawan, 2003: 253). Lozanov menyarankan menggunakan musik barok untuk pembelajaran karena musik barok tidak memiliki lirik dan bersifat netral, selain itu irama musik barok dapat menenangkan dan memiliki pengaruh kuat pada kemampuan untuk menyerap informasi dan menghafalnya (Rose \& Nicholl, 1997).

Permasalahan yang diuraikan di atas membuat peneliti tertarik untuk membuktikan bahwa kemampuan membaca pemahaman siswa dapat ditingkatkan dengan penerapan Accelerated Leanring berbasis musik barok. Tujuan penelitian ini untuk mengetahui perbandingan kemampuan membaca pemahaman antara siswa yang belajar dengan Accelerated Learning berbasis musik barok dengan yang tidak dan untuk mengetahui pengaruh musik barok terhadap pembelajaran yang dilaksanakan siswa.

\section{TINJAUAN PUSTAKA}

\section{Hakikat Kemampuan Membaca Pemahaman}

Al Odwan (2012) berpendapat bahwa kemampuan membaca pemahaman adalah sebuah proses untuk memecahkan kode melalui pengembangan kata dan belajar memahami isi suatu teks.

Turner (Somadayo, dkk., 2013) mengungkapkan bahwa pembaca dapat dikatakan memiliki pemahaman yang baik dari bahan bacaan yang dibacanya jika pembaca dapat (1) mengenali katakata atau kalimat dalam bacaan dan mengetahui maknanya, menghubungkan pengetahuan sebelumnya dengan pengetahuan baru yang didapat dari kegiatan membaca, (3) memahami keseluruhan secara kontekstual, dan (4) membuat kesimpulan pada isi bahan bacaan berdasarkan bacaannya.

Nutall menyatakan bahwa tujuan membaca pemahaman adalah bagian dari proses membaca pemahaman itu sendiri. Hal itu ditandai saat pembaca memahami pesan dan makna yang ada dalam sebuah teks bacaan yang telah ia baca. Selanjutnya, pesan atau makna yang disampaikan bisa dalam bentuk informasi maupun pengetahuan (Somadayo, dkk., 2013).

Siswa kelas V sekolah dasar berada pada tingkatan pemahaman interpretatif. Tingkatan interpretatif merupakan pemahaman yang melibatkan keterampilan berpikir dan mengidentifikasi alasan-alasan, menemukan hubungan, meramalkan penyelesaian (ending), dan memperbandingkan, serta mampu memahami maksud penulis secara tersurat maupun tersirat (Dalman, 2014: 99).

\section{Hakikat Accelerated Learning}

Accelerated Learning pertama kali dikembangkan oleh seorang peneliti pendidikan psikiatris dari Bulgaria, Dr. Georgi Lozanov. Sampai saat ini pengembangan Accelerated Learning masih di lakukan oleh peneliti pendidikan dari Harvard, Dr. Howard Gardner. Meier (2000) mengungkapkan bahwa pembelajaran harus dikemas secara menarik. Dalam pembelajaran, ada saatnya untuk bermain dan ada pula 
saatnya untuk serius. Pembelajaran yang efektif harus bisa menyeimbangkan keduanya, dan kedua hal tersebut dikemas secara menarik dalam Accelerated Learning.

Vos (Rose and Nicholl, 1997) mengatakan "Accelerated Learning gives you the freedom to learn. It helps you to tap into that genius that all of us have", Accelerated Learning memberikan kebebasan dalam belajar. Hal itu dapat membantu kita untuk mencapai kecerdasan yang kita miliki. Ganiron Jr. (2013) mengatakan bahwa Accelerated Learning dilaksanakan untuk meningkatkan kualitas pembelajaran dengan cara meningkatkan keaktifan siswa, kerjasama, dan kemampuan memecahkan masalah.

Bethens (2016) menyatakan cara untuk membuat belajar menjadi lebih efektif yaitu: (1) memusatkan perhatian pada apa yang akan dipelajari, (2) menghilangkan gangguan belajar, (3) mencatat materi pelajaran, (4) menjelaskannya pada orang lain, (5) mengajukan pertanyaan untuk mengukur tingkat kemampuan, dan (6) merealisasikannya dalam kehidupan sehari-hari. Cara-cara tersebut ada dalam pembelajaran Accelerated Learning, sehingga dengan menerapkan Accelerated Learning dalam pembelajaran akan membuat belajar siswa menjadi lebih efektif.

Prinsip-prinsip Accelerated Learning menurut Meier (2000) yaitu sebagai berikut: (1) belajar merupakan kreativitas, bukan konsumsi. Pengetahuan bukan sesuatu yang abstrak, tapi sesuatu yang harus di ciptakan. Aktivitas belajar terjadi apabila adanya hubungan antara pengetahuan yang sudah ada dengan pengetahuan baru yang akan didapatkan, (2) belajar berkolaborasi. Belajar secara berkelompok lebih baik daripada belajar secara individu, karena proses belajar di dasari oleh interaksi sosial. Interaksi sosial dalam pembelajaran kelompok di sini yaitu antara guru dengan peserta didik, (3) belajar membutuhkan multisimultan. Belajar bukanlah menerima banyak informasi dalam satu waktu, (4) belajar merupakan kegiatan yang dialami sendiri (serta timbal baliknya). Memberikan pengalaman konkret agar siswa mengalami sendiri apa yang akan dipelajari akan membuat siswa menyerap informasi dengan baik.

Langkah-langkah penerapan Accelerated Learning menurut Rose and Nicholl (1997) ada enam yang biasa disingkat MASTER, yaitu (1) Motivating your mind, (2) Acquiring the information, (3) Searching out of the meaning, (4) Triggering the memory, (5) Exhibition what you know, dan (6) Reflecting on how you've learned. Untuk lebih jelasnya diuraikan sebagai berikut:

a. Motivating your mind (Memotivasi pikiran)

Sebelum pembelajaran dimulai, guru membawa siswa dalam keadaan rileks, percaya diri dan memotivasi siswa untuk memperoleh informasi. Guru meminta siswa untuk menghirup udara dalam-dalam dan merasakan udara yang dihirupnya, memejamkan matanya, kemudian guru mulai memutar musik barok. Hal ini ditujukan agar pikiran siswa dalam keadaan rileks dan membawa siswa pada keadaan gelombang alfa. Pada tahap ini guru membuat kesepakatan kontrak belajar dengan siswa, kemudian guru mengaitkan materi pembelajaran dengan pengetahuan awal siswa. Pada tahap ini juga guru membagi siswa menjadi kelompok dan meminta setiap kelompok untuk membuat motto kelompok dalam satu kata.

b. Acquiring the information
(Memperoleh informasi) 
Setiap individu memiliki caranya masing-masing untuk memperoleh fakta-fakta dalam suatu pembelajaran. Meskipun cara yang digunakan setiap individu berbeda-beda, kunci utamanya yaitu pada kegiatan melihat, mendengar dan terlibat dalam proses pembelajaran itu sendiri. Hal ini dilakukan agar siswa lebih mudah menyerap dan memperoleh informasi dari suatu pembelajaran. Pada tahap ini guru memberikan bahan bacaan pada setiap kelompok. Setiap kelompok akan mendapat beberapa kartu pertanyaan dan gambar sketsa benda-benda alam. Siswa menuliskan jawaban dari kartu pertanyaan di gambar sketsa bendabenda alam, kemudian jawaban tersebut ditempelkan pada lembar kerja sesuai kreativitas siswa.

c. Searching out of the meaning (Menyelidiki makna)

$\begin{array}{ccc}\text { Agar informasi } & \text { yang } \\ \text { didapat bisa } & \text { tertanam secara }\end{array}$ permanen dalam otak, kita harus mencari makna dari pembelajaran yang sedang dilakukan. Pada tahap ini, kegiatan yang dilakukan adalah perwakilan kelompok memaparkan hasil diskusinya di depan kelas. Setelah itu siswa bersama guru bertanya jawab tentang cara untuk menemukan makna dalam suatu bacaan.

d. Triggering the memory (Memicu ingatan)

Pastikan materi pembelajaran yang disampaikan oleh guru telah sampai pada pikiran siswa. Tidak hanya pada pikiran sadar siswa, tapi juga pada pikiran tak sadar siswa. Karena dengan menyimpan memori dalam pikiran tak sadar, siswa akan mengingatnya secara permanen dan dapat menyampaikannya sewaktu-waktu saat dibutuhkan. Pada tahap ini, siswa bersama guru menyamakan persepsi mengenai bagaimana cara menemukan makna dalam suatu bacaan dan siswa mencatat hal-hal penting mengenai materi pembelajaran.

e. Exhibition what you know (Memamerkan yang telah diketahui)

Pada tahap ini siswa memamerkan apa yang telah diketahuinya atau dipahaminya dengan cara mengerjakan soal tes yang diberikan oleh guru sesuai dengan materi pembelajaran. Dari hasil tes inilah guru bisa mengetahui apakah siswa benarbenar telah memahami materi pembelajaran yang telah dilakukan.

f. Reflecting on how you've learned (Merefleksi apa yang telah dipelajari)

Tahap ini dilaksanakan pada akhir pembelajaran, guru menyimpulkan dan merefleksi konsep pembelajaran yang telah dilaksanakan. Refleksi dalam proses pembelajaran diperlukan untuk mengetahui kemampuan siswa dalam menyerap informasi yang telah ia dapatkan selama proses pembelajaran.

\section{Hakikat Musik Barok}

Penerapan

Accelerated

Learning didasarkan pada pembelajaran yang menggunakan musik pengiring selama pembelajaran. Fungsi musik selama pembelajaran untuk menstimulasi otak dalam keadaan alpha dan beta. Gelombang alpha terjadi pada saat seseorang mengalami relaksasi atau mulai istirahat, sedangkan gelombang beta diperlukan ketika otak berpikir rasional dan memecahkan suatu masalah.

Clynes (Jensen, 2008: 378) menjelaskan bagaimana musik melibatkan seluruh bagian otak. Struktur harmonik, kualitas interval, warna nada, dan pola-pola spasial, 
temporal dan jangka panjang dari musik dikenali oleh belahan otak nondominan (otak kanan). Di sisi lain, melodi jangka pendek dalam musik seperti variasi volume, rute titi nada yang akurat dan cepat, hitungan langkah nada, dan lirik dikenali oleh belahan otak dominan (otak kiri).

$$
\text { Pelaksanaan Accelerated }
$$

Learning diiringi oleh musik. Musik dalam pembelajaran Accelerated Learning berjenis musik baroque. Lozanov menemukan bahwa ritmis musik barok/baroque menenangkan dan memiliki dampak yang kuat pada kemampuan kita untuk menyerap informasi dan mengingatnya (Rose and Nicholl, 1997). Istilah baroque merujuk pada suatu zaman sekitar tahun 16001750. Komposer yang terkenal pada masa ini yaitu komposer Jerman, Johan Sebastian Bach (1685-1750) dan George Friedrich Handel (1685-1759) dan seorang komposer Italia, Antonio Vivaldi (1678-1741). Musik yang dihasilkan sangat unik, karena musik yang diciptakan mampu membawa otak ke kondisi beta maupun alfa (Gunawan, 2003: 252).

Gunawan (2003: 252) juga menjelaskan bahwa musik baroque digunakan oleh Dr. Georgi Lozanov pada masa awal ia mengembangkan teknik belajar yang dikenal Accelerated Learning. Musik baroque dibagi menjadi dua kategori, yaitu quick baroque (antara 100-140 bit per menit) yang digunakan untuk brain-storming, diskusi atau tugas yang menuntut output kreatif, dan slow baroque (antara 55-70 bit per menit) yang digunakan dalam proses pemasukan informasi.

Schuster dan Gritton menyatakan bahwa kebanyakan musik baroque sesuai dengan detak jantung manusia yang santai dalam kondisi belajar optimal. Musik ini mempengaruhi pikiran tak sadar, merangsang reseptivitas dan persepsi. Penggunaan musik baroque dalam pendidikan berpengaruh untuk menata suasana hati, meningkatkan hasil belajar yang diinginkan, dan menyoroti hal-hal penting (DePorter, Reardon, dan Nourie, 2005: 73-74).

Penggunaan musik barok dalam pembelajaran melalui beberapa tahapan, yaitu (1) sebagai pembuka pembelajaran, (2) sebagai pembatas waktu saat guru memberikan dan menjelaskan tugas pada siswa, (3) sebagai pembangkit semangat siswa dalam belajar, (4) sebagai pengarah visualisasi saat siswa sedang membaca, (5) sebagai pengiring diskusi saat siswa berdiskusi kelompok untuk memecahkan masalah, (6) sebagai pengiring diskusi saat siswa berdiskusi bersama guru, dan (7) sebagai penutup pembelajaran (Gunawan, 2003: 261268).

\section{METODOLOGI PENELITIAN}

\section{Subjek Penelitian}

Penelitian dilaksanakan di sekolah dasar dengan subjek penelitian berjumlah 52 siswa kelas V. Sampling pada penelitian ini ditentukan secara non-random. Berikut disajikan tabel jumlah partisipan dalam penelitian ini.

Tabel 1. Jumlah partisipan penelitian

\begin{tabular}{lc}
\hline \multicolumn{1}{c}{ Kelas } & Jumlah \\
\hline Kontrol & 26 \\
\hline Eksperimen & 26 \\
\hline Total & 52 \\
\hline
\end{tabular}

\section{Pengumpulan Data}

Data yang dikumpulkan berupa skor tes membaca pemahaman siswa sebelum dan sesudah dilaksanakan treatment dengan Accelerated Learning berbasis musik barok. Data dikumpulkan menggunakan tes melalui lembar tes yang berisi pertanyaanpertanyaan tentang pemahaman bacaan. Tes pemahaman bacaan berupa soal pilihan ganda dan pertanyaan terbuka. 
Setelah dikumpulkan, data dianalisis menggunakan independent sample $t$ test yang sebelumnya telah diuji normalitas dan homogenitasnya dengan bantuan PASW Statistic 18.

\section{Method}

Penelitian ini menggunakan metode quasi eksperimen dengan desain nonequivalent control group. Tujuan utama rancangan eksperimen untuk menguji dampak suatu treatment terhadap hasil penelitian, yang dikontrol oleh factor lain yang mungkin juga memengaruhi hasil tersebut (Creswell, 2013: 216). Desain nonequivalent control group, menyeleksi kelompok eksperimen dan kelompok control tanpa prosedur penempatan acak. Kedua kelompok sama-sama diberikan pretest dan posttest, hanya pada kelompok eksperimen diberikan treatment (Creswell, 2013: 242). Berikut disajikan gambar desain dalam penelitian ini.

\begin{tabular}{|ll}
\hline Kelompok A & $\mathrm{O}_{1}-\mathrm{X}-\mathrm{O}_{2}$ \\
\hline Kelompok B & $\mathrm{O}_{1} \longrightarrow \mathrm{O}_{2}$
\end{tabular}

Gambar 1. Desain Penelitian (Sumber: Creswell, (2017: 242)).

\section{HASIL DAN PEMBAHASAN}

\section{HASIL PENELITIAN}

Data yang diperoleh yaitu berupa skor pretest dan posttest kemampuan membaca pemahaman siswa. Indikator membaca pemahaman yang diukur dalam tes sesuai dengan yang diuraikan Caldwell (2008), yaitu siswa mampu mengungkapkan informasi yang tersirat dalam bacaan, oleh karena itu bentuk tesnya berupa pertanyaan-pertanyaan baik pilihan ganda maupun pertanyaan terbuka mengenai unsur-unsur cerita anak. Pembelajaran dilaksanakan dengan langkah-langkah Accelerated Learning yang diiringi music barok selama pembelajaran. Berikut disajikan deskripsi data penelitian.

Tabel 2. Deskripsi Data Penelitian

\begin{tabular}{|l|r|r|r|r|r|}
\hline \multicolumn{7}{|c|}{ Descriptive Statistics } \\
\hline & \multicolumn{1}{|c|}{ N } & Minimum & Maximum & Mean & Std. Deviation \\
\hline Pretest Experiment & 26 & 27 & 89 & 64.08 & 14.508 \\
Posttest Experiment & 26 & 67 & 97 & 87.27 & 7.242 \\
Prettest Control & 26 & 36 & 90 & 67.42 & 11.937 \\
Postlest Control & 26 & 43 & 94 & 81.00 & 11.634 \\
Valid N (listwise) & 26 & & & & \\
\hline
\end{tabular}

Kelas kontrol maupun kelas eksperimen mengalami peningkatan skor membaca pemahaman. Untuk lebih jelasnya, berikut disajikan gambar perbandingan rata-rata skor membaca pemahaman siswa.

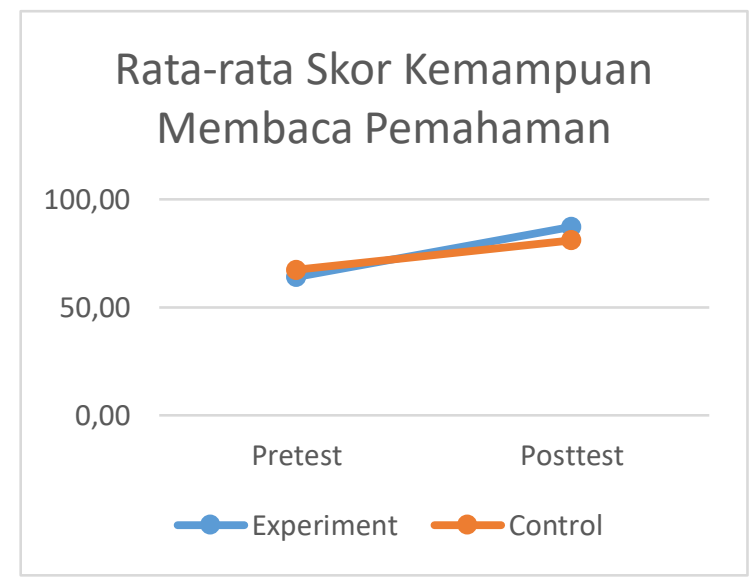

Gambar 2. Perbandingan Rata-rata Skor Membaca Pemahaman

Gambar tersebut menunjukkan adanya peningkatan kemampuan membaca pemahaman siswa saat pretest sampai posttest. Kelas eksperimen yang melaksanakan treatment dengan Accelerated Learning yang diiringi musik barok skor rata-ratanya lebih tinggi dibandingkan dengan kelas kontrol yang tidak melaksanakan treatment.

Sebelum melakukan pengujian hipotesis, data diuji prasayarat yang berupa uji normalitas yang 
menggunakan teknik Kolmogorovsmirnov dan homogenitas dengan bantuan PASW Statistics 18. Hasil uji prasyarat menunjukkan bahwa data berdistribusi normal dan homogen. Oleh karena itu, pengujian dilanjutkan dengan menggunakan independent sample t-test dengan dasar pengambilan keputusan yaitu jika asymp.sign (2-tailed) $<0,05$ maka terdapat perbedaan rata-rata pada kelas kontrol dan eksperimen; dan jika asymp.sign (2-tailed) > 0,05 maka tidak terdapat perbedaan. Berdasarkan analisis yang telah dilakukan, diperoleh hasil yang dapat dilihat pada tabel berikut.

Tabel 3. Hasil Uji Independent Sample $\mathrm{T}$ Test

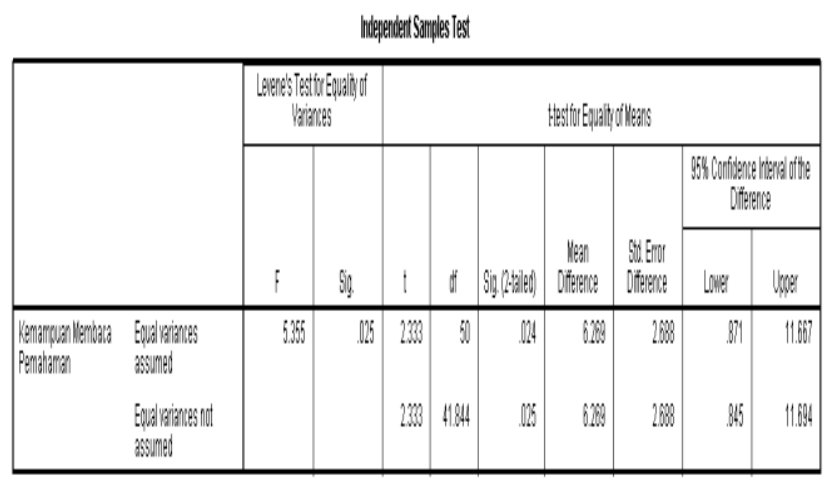

Hipotesis yang diajukan adalah:

(1) H0: rerata skor siswa kelas eksperimen tidak lebih baik daripada kelas kontrol, dan (2) Ha: rerata skor siswa kelas eksperimen lebih baik daripada kelas kontrol. Kriteria pengujian tolak H0 jika p-value (sig.) < $\alpha=0,05$. Karena nilai $p$-value $=0,024<$ 0,05 berarti tolak $\mathrm{H}_{0}$ yang artinya terdapat perbedaan rata-rata antara dua sampel tersebut, rerata skor kelas eksperimen lebih baik daripada kelas kontrol

\section{PEMBAHASAN}

Musik barok mengiringi pembelajaran membaca dari awal sampai akhir pembelajaran. Musik lebih ditekankan pada saat kegiatan siswa, seperti membaca dalam hati, berdiskusi, mencatat hal-hal penting, dan mengerjakan tugas. Materi-materi yang menjadi bahan tes membaca pemahaman, meliputi: garis besar isi teks bacaan, persamaan isi dua teks bacaan, perbedaan isi dua teks bacaan, menyimpulkan isi dua teks bacaan, menyebutkan tokoh-tokoh cerita anak, perwatakan tokoh, latar, amanat, menyimpulkan isi cerita, dan menjawab pertanyaan berdasarkan isi cerita anak.

Pada awal pembelajaran guru belum mengarahkan siswa untuk menikmati musik di awal pembelajaran, siswa juga masih belum terbiasa dengan adanya musik selama proses pembelajaran. Siswa mengaku senang belajar dengan diiringi musik. Hal tersebut membuat mereka merasa lebih bersemangat untuk belajar dan siswa tidak terganggu dengan adanya musik selama pembelajaran.

Kemampuan

membaca pemahaman siswa masih belum menunjukkan adanya perbaikan, siswa belum memahami materi dengan baik, terlihat saat guru mengajukan pertanyaan mengenai garis besar isi teks bacaan dan siswa bingung untuk menjawabnya. Padahal menurut Gooden, Carreker, Thornhill, \& Joshi (2007), kemampuan membaca pemahaman salah satunya dapat diukur dengan menjawab pertanyaan mengenai isi bacaan. Siswa juga belum bisa menentukan garis besar isi teks bacaan dengan tepat, padahal menurut Brown (Somadayo, dkk., 2013) pembaca dikatakan sudah memahami isi teks bacaan, jika pembaca dapat menentukan garis besar isi teks bacaan, bahkan siswa merasa kesulitan saat diminta untuk menyimpulkan isi teks bacaan.

Siswa mulai menikmati musik barok selama pembelajaran, namun masih ada beberapa siswa yang terlihat malas saat kegiatan membaca. Siswa terlihat masih belum memahami persamaan dan perbedaan isi dua teks bacaan dengan baik, hal ini terlihat saat 
guru meminta siswa untuk menjelaskan persamaan dan perbedaan isi dua teks bacaan, namun hanya beberapa siswa yang bisa menjelaskannya.

Pemahaman siswa mengenai isi bacaan semakin meningkat, terlihat saat guru mengajukan pertanyaan mengenai persamaan, perbedaan, dan kesimpulan isi dua teks bacaan, siswa sudah bisa menjawab, meskipun belum tepat seluruhnya. Siswa yang kurang termotivasi dalam belajar akan berdampak pada pemahamannya terhadap bacaan, sebagaimana yang diungkapkan oleh Tuckerman (2003) bahwa siswa yang tidak termotivasi dengan baik, tidak dapat belajar secara efektif.

Siswa mampu menjawab pertanyaan guru mengenai pemahaman isi teks bacaan, siswa berani mengemukakan perbedaan pemahamannya dengan kelompok penyaji saat kegiatan presentasi, dan siswa mampu menjelaskan jawabannya saat membahas soal-soal evaluasi bersama guru. Kegiatan tanya jawab yang dilakukan oleh guru dan siswa didukung dengan pendapat Nur (Effendi, 2016) bahwa seringnya guru mengakses pemahaman siswa dengan mengajukan banyak pertanyaan, siswa termotivasi untuk menjawab pertanyaan.

Blake (2014) menyatakan salah satu cara untuk meningkatkan kemampuan membaca pemahaman yaitu dengan banyak melakukan latihan. Latihan yang dilaksanakan dalam penelitian ini, yaitu guru melatih siswa dengan cara mengajukan pertanyaan pada siswa, membimbing siswa saat membaca teks bacaan, meminta kelompoknya untuk membagi tugas dan membantu temannya yang kesulitan mengerjakan tugas saat diskusi kelompok, guru juga meminta siswa untuk mempresentasikan hasil diskusi bersama kelompoknya di depan kelas, membimbingnya untuk membaca dan menjawab pertanyaan mengenai pemahaman isi bacaan, guru juga banyak mengajukan pertanyaan yang berkaitan dengan pemahaman isi teks bacaan pada siswa dan membimbing siswa agar bisa menjawab dengan tepat. Dengan terus melakukan latihan, akhirnya kemampuan membaca pemahaman siswa dapat meningkat.

Penggunaan musik barok dalam pendidikan berpengaruh untuk menata suasana hati, meningkatkan hasil belajar yang diinginkan, dan menyoroti hal-hal penting (DePorter, Reardon, dan Nourie, 2005: 73-74). Penggunaan musik barok untuk membantu proses Accelerated Learning dalam penelitian ini sesuai dengan pendapat Gunawan (2003: 261-268), diantaranya sebagai berikut:

1) Musik sebagai pembukaan, digunakan untuk membantu mempengaruhi mood dan atmosfir belajar;

2) Musik sebagai pembatas waktu, digunakan saat guru memberikan tugas pada siswa;

3) Musik untuk membangkitkan semangat dan energi, digunakan saat suasana kelas terlihat bosan dan siswa merasa mengantuk;

4) Musik untuk relaksasi, digunakan untuk membuat siswa rileks setelah mengerjakan tugas/latihan soal yang diberikan oleh guru

5) Musik untuk membantu dan mengarahkan visualisasi, digunakan untuk membantu siswa merasa rileks selama kegiatan membaca;

6) Musik untuk membantu diskusi, digunakan untuk menciptakan suasana yang mendukung proses diskusi;

7) Musik untuk konser aktif, digunakan saat guru membacakan informasi dengan dramatis dan penuh emosi; 
8) Musik untuk penutup, digunakan setelah siswa selesai belajar dan bersiap mengakhiri pembelajaran.

\section{KESIMPULAN}

Accelerated Learning berbasis musik barok terbukti dapat meningkatkan kemampuan membaca pemahaman siswa. Hasil penelitian juga menunjukkan adanya perbedaan skor kemampuan membaca pemahaman pada kelas kontrol dan kelas eksperimen, dimana skor akhir kelas eksperimen yang mendapatkan treatment berupa penerapan Accelerated Learning berbasis musik barok lebih baik dibandingkan skor kelas kontrol.

Musik barok yang diperdengarkan selama pembelajaran juga memberikan dampak positif bagi siswa, musik tidak mengganggu jalannya pembelajaran dan tidak memecah konsentrasi siswa. Kegiatan membaca dalam pembelajaran yang diiringi musik barok dapat meningkatkan motivasi dan minat siswa dalam membaca dan mampu meningkatkan konsentrasi siswa yang berakibat pada adanya peningkatan pemahaman siswa terhadap isi bacaan.

\section{Acknowledgements}

Saya berterima kasih pada Tuhan Yang Maha Esa yang telah melimpahkan rahmat dan karuniaNya sehingga saya dapat menyelesaikan artikel ini tepat waktu. Saya juga berterima kasih pada orangorang yang telah memberikan dukungan dan bantuannya sampai akhirnya artikel ini dapat terselesaikan dengan baik.

\section{REFERENSI}

Al Odwan, T. A. A. H. (2012). The effect of the directed reading thinking activity through cooperative learning on English secondary stage students' reading comprehension in Jordan. International Journal of Humanities and Social Science, 2(16), 138-151.

Alvermann, D. E. and Earle, J. (2003). Comprehension instruction. In A.P.
Sweet and C. Snow (Eds.), Rethinking reading comprehension. New York: Guilford.

Bethens, T. (2016). Accelerated Learning The Best Accelerated Learning Techniques To Learn More, Improve Memory, Enhance Intellect, and Process Information Faster.

Blake, D. (2014). Accelerated Learning Techniques for Beginners: Effective Tips to Improve Your Memory and Reading Comprehension, Learn More and Faster, Enhance Intellect. New York: United States of America.

Caldwell, J., S. (2008). Comprehension Assessment, a Classroom Guide. New York: The Guilford Pub.

Creswell, J. W. (2013). Research Design: Pendekatan Kualitatif, Kuantitatif, dan Mixed Methods. New York: SAGE Publications.

Dalman. (2015). Menulis karya ilmiah. Depok: Rajagrafindo Persada

DePorter, B., Reardon, M., \& Nourie, S. S. (2005). Quantum Teaching Mempraktikkan Quantum Learning di Ruang-ruang Kelas. Terj. A. Nilandari. Bandung: Kaifa.

Effendi, M. (2016). Peningkatan Aktivitas Dan Hasil Belajar Matematika Melalui Model Pembelajaran Berdasarkan Masalah (Problem Based Learning) Pada Peserta Didik Kelas VI SDN 04 Nan Sabaris Tahun Pelajaran 2015/2016. Jurnal Konseling dan Pendidikan, 4 (2), 5257.

Ganiron Jr, T. U. (2013). Application of Accelerated Learning in Teaching Environmental Control System in Qassim University. International Journal of Education and Learning, 2 (2), 27-38.

Gooden, B. R., Carreker, S., Thornhil, A., and Joshi, M. (2007). Instruction of metacognitive strategies enhances reading comprehension and vocabulary achievement of third grade students. The Reading Teacher, 61 (1), 70-77. 
Gunawan, A. W. (2003). Genius Learning Strategy. Jakarta: Gramedia.

Jensen, E. (2008). Brain Based Learning. Terj. Narulita Y. Yogyakarta: Pustaka Pelajar. (Buku asli diterbitkan 2007)

Mason, R. (2004). Online education using learning objects. British Journal of Educational Technology, 35(6), 752754.

Meier, D. (2000). The Accelerated Learning Handbook. New York: McGraw Hill Inc.

Oakhil, J., Cain, K., \& Elbro, C. 2015. Understanding and Teaching Reading Comprehension: a Handbook. New York: Routledge.

OECD. 2018. PISA 2015 Results in Focus. Diperoleh dari situs https://www.oecd.org/pisa/pisa2015-results-in-focus.pdf pada tanggal 15 Mei 2018.

Rose, C. \& Nicholl, M. J. (1997). Accelerated Learning for the $21^{\text {st }}$ Century The Six-Step to Unlock Your Master-Mind. New York: Dell Publishing.

Sari, A. A. 2015. Using Structural Equation Modeling to Investigate Students' Reading Comprehension Skills. Elementary Education Online, 14 (2), 511-521.

Somadayo, S., dkk. (2013). The Effect of Learning Model DRTA (Directed Reading Thinking Activity) Toward Students' Reading Comprehension Ability Seeing from Their Reading Interest. Journal of Education and Practice, 4 (8), 115-122.

Tuckerman, B. W. (2003). The effect of learning and motivation strategies training on college students' achievement. Journal of College Student Development, 44(3), 430437.

Woolley, G. 2011. Reading Comprehension Assisting Children with Learning Difficulties. New York: Springer Science. 